Review

\title{
Is Digital Twin Technology Supporting Safety Management? A Bibliometric and Systematic Review
}

\author{
Giulio Paolo Agnusdei ${ }^{1,2, *(\mathbb{C})}$, Valerio Elia ${ }^{1}$ and Maria Grazia Gnoni ${ }^{1}[$ \\ 1 Dipartimento di Ingegneria dell'Innovazione, Università del Salento, via per Monteroni, 73100 Lecce, Italy; \\ valerio.elia@unisalento.it (V.E.); mariagrazia.gnoni@unisalento.it (M.G.G.) \\ 2 Department of Mechanical and Industrial Engineering, Norwegian University of Science and Technology, S.P. \\ Andersens vei, 5, NO-7491 Trondheim, Norway \\ * Correspondence: giulio.agnusdei@unisalento.it
}

check for updates

Citation: Agnusdei, G.P.; Elia, V.; Gnoni, M.G. Is Digital Twin Technology Supporting Safety Management? A Bibliometric and Systematic Review. Appl. Sci. 2021, 11, 2767. https://doi.org/10.3390/ app11062767

Academic Editor: A.Y.C. Nee

Received: 26 February 2021

Accepted: 18 March 2021

Published: 19 March 2021

Publisher's Note: MDPI stays neutral with regard to jurisdictional claims in published maps and institutional affiliations.

Copyright: (c) 2021 by the authors. Licensee MDPI, Basel, Switzerland. This article is an open access article distributed under the terms and conditions of the Creative Commons Attribution (CC BY) license (https:/ / creativecommons.org/licenses/by/ $4.0 /)$.

\begin{abstract}
In the Industry 4.0 era, digital tools applied to production and manufacturing activities represent a challenge for companies. Digital Twin (DT) technology is based on the integration of different "traditional" tools, such as simulation modeling and sensors, and is aimed at increasing process performance. In DTs, simulation modeling allows for the building of a digital copy of real processes, which is dynamically updated through data derived from smart objects based on sensor technologies. The use of DT within manufacturing activities is constantly increasing, as DTs are being applied in different areas, from the design phase to the operational ones. This study aims to analyze existing fields of applications of DTs for supporting safety management processes in order to evaluate the current state of the art. A bibliometric review was carried out through VOSviewer to evaluate studies and applications of DTs in the engineering and computer science areas and to identify research clusters and future trends. Next, a bibliometric and systematic review was carried out to deepen the relation between the DT approach and safety issues. The findings highlight that in recent years, DT applications have been tested and developed to support operators during normal and emergency conditions and to enhance their abilities to control safety levels.
\end{abstract}

Keywords: safety; digital twin; smart operator; smart manufacturing; Industry 4.0

\section{Introduction}

The fourth industrial revolution-also known as the Industry 4.0 paradigm-is changing current industrial production systems. The Industry 4.0 digital transformation is aimed at the optimization and automation of the previously introduced digitalization by adding the intelligent networking of machines, processes, and people [1]. In recent years, the concepts and theories of Industry 4.0 have become considerably important within the manufacturing sector [2]. One main reason for this increasing diffusion is the use and implementation of hi-tech technologies within the production processes at an affordable cost [3] in order to create smart grids across the entire value chain and networks formed by interconnecting intelligent machines [4]. Within industrial manufacturing contexts, Industry 4.0 entails the networking of data coming from machines, products, and people; in general, this involves the interconnection of smart devices among different plants and factories [5] through tools and embedded components, such as cyber-physical systems (CPSs), Internet of Things (IoT), cloud computing, robotics, systems based on artificial intelligence, and cognitive computation [4].

Digital Twins (DTs) are key enabling technologies (KETs) that were created to improve the efficiency and profitability of Industry 4.0 systems [6,7].

The first applications of DTs in industrial systems focused on developing a "digitalized copy" of a production process and/or a product. More recently, through the overlapping with the IoT, DT functionality and interoperability has been "augmented" by adding a real-time interaction with the real system [1]. 
The availability of virtual and digital information represents an effective solution for improving product design, manufacturing technology, and other critical service processes, such as safety management [8,9].

Safety management, as the process of realizing certain safety functions, aims to promote organizational safety and to protect people and property within an organization from unacceptable safety risks [10]. Recently, with the increasing global economic uncertainties, safety management in most organizations is under growing pressure to achieve the best performance, and this requires access to a variety of high-quality safety information [11].

In the era of Industry 4.0, it cannot be disputed that data and information represent an indispensable resource and a successful key factor for a new paradigm of safety management [12-15].

Within the Safety 4.0 framework [16], DT-assisted safety management systems can be implemented to help operators execute complex safety procedures, thus reducing risks and human errors. DT guidance can lead operators through safety tasks and provide them with real-time information regarding the contextual conditions [17]. This can reduce the costs and time required for service and maintenance, decrease oversights and mistakes, and increase safety $[18,19]$.

The main purpose of this study is to present the prevailing state of research on Digital Twin technology, its manifold applications, and the intersection between DTs and safety, answering the following research questions:

RQ1. What are the current publication trends in the domain in terms of the types of studies, time, and affiliated countries?

RQ2. Which are the influential studies and themes of research in this domain and how have they evolved over the years?

RQ3. What are the recent research trends, gaps, and areas for future research in this domain?

The rest of this paper is organized as follows: Section 2 delineates the advent of DTs, their main features, and their background. Section 3 illustrates the adopted methodological framework, while Section 4 covers the findings on the publication trends and on the keyword and cluster content analyses. The study is concluded in Section 5, where future research avenues are suggested.

\section{Background}

The DT concept first appeared in the aerospace field around the 1970s (Figure 1); the first complete characterization was proposed by Grieves during a course on Product Lifecycle Management at the University of Michigan [20].

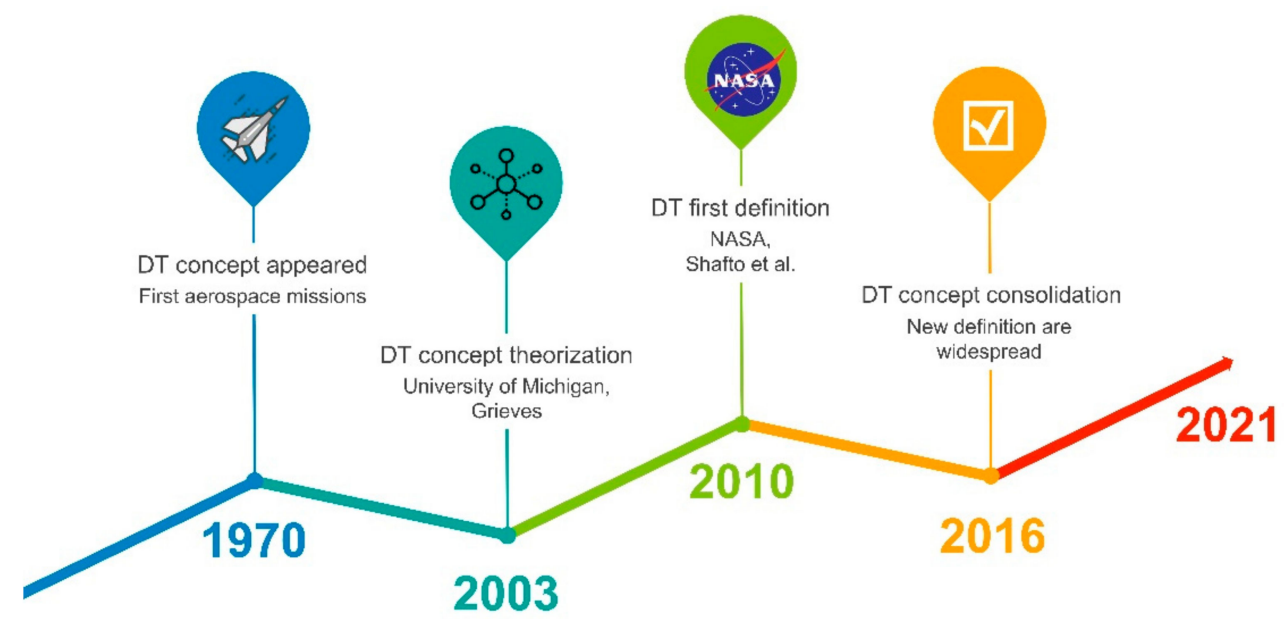

Figure 1. The timeline of the evolution of the definition of a Digital Twin (DT). 
Basically, a DT refers to a system consisting of three main subsystems: (a) physical products in real space, (b) virtual products in virtual space, and (c) data and information that tie the virtual and real products together. Grieves [20] depicted DT flow as a cycle between the physical and virtual states (called twinning), with data flowing from the physical to the virtual and information and processes flowing from the virtual to the physical states (Figure 2).

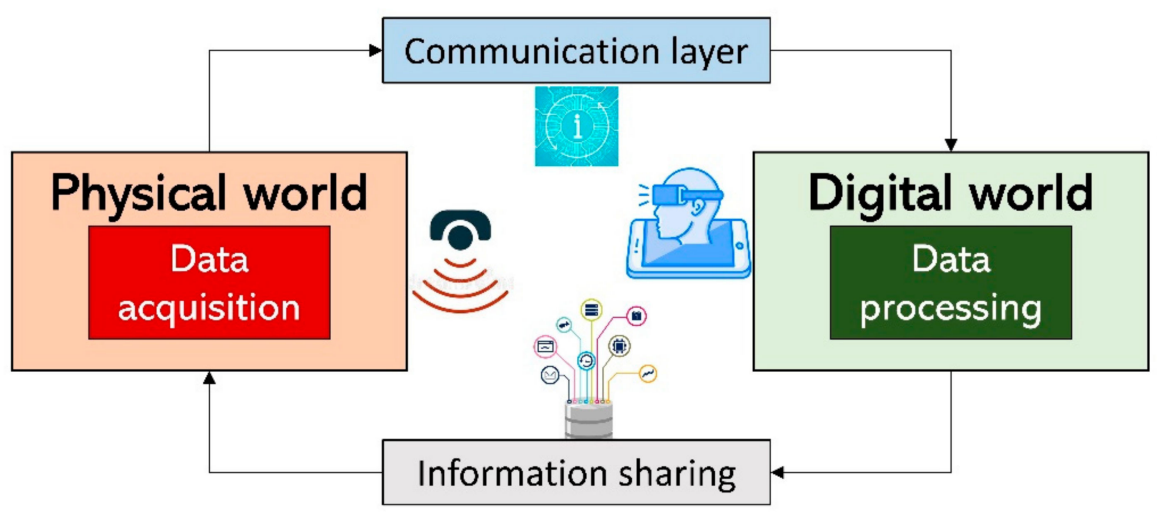

Figure 2. Digital Twin concept.

Then, NASA provided the first definition of a DT for the aeronautic sector [21]: A "digital twin is an integrated multi-physics, multi-scale, probabilistic simulation of a vehicle or system that uses the best available physical models, sensor updates, fleet history, etc., to mirror the life of its flying twin".

Differently from the first definition, this one referred explicitly to the concept of simulation modeling, which is often adopted in several tools for supporting the design, validation, and testing of a system. Within this definition, the simulation is considered as a multi-physics model, as more than one physical field is simultaneously involved and different physical properties are integrated; simulation modeling is also usually multi-scale because different levels of time and/or space are used; finally, it is probabilistic because it could easily be developed with probability calculations.

These features characterize traditional simulation models, and they are enhanced in DT applications due to their stricter connection with the physical world.

Traditional simulation models are developed based on real data, but their updating is usually a static process [22]. Differently, in DTs, a data update process is required, and this represents the most relevant feature of DTs. Thus, due to the diffusion of the Industry 4.0 paradigm, a huge amount of data about physical systems are now available—even in real time - to be used for operation redesign and control. This availability is becoming the main key enabler of DT system development in manufacturing systems.

From 2010 onwards, the definition of DTs given by NASA was modified, and new definitions that were more focused on the industrial sector were proposed in the scientific literature. Lee et al. [23] proposed DTs as an advancement in predictive manufacturing systems. In their definition, the DT is defined as a simulation model that acquires real data and transfers them to a simulator in the cloud. In line with this study, Rosen et al. [24] stated that DTs, by combining real data with simulation models, allowed for the drawing up of a forecast based on realistic data, thus providing a sort of guidance system that supports operators and planners during normal operation, as well as during maintenance and service. Chen [25] described the DT as a computerized model of a physical device or system that represents all functional features and links with the working elements.

In 2018, some authors identified the Digital Twin as a digital representation of a physical production system that uses integrated simulations and service data, holding information from multiple sources across a product's life cycle. This information is continuously updated based on operational changes and is visualized in different ways to forecast 
current and future conditions of the physical counterpart in order to enhance decision making [26,27].

Recently, one of the latest definitions identified the Digital Twin as a virtual instance of a physical system (twin) that is continually updated with the latter's performance, maintenance, and health status data throughout the physical system's life cycle [28].

As a promising means of achieving cyber-physical interaction, integration, and fusion, Digital Twins (DTs) have captured growing attention from academic researchers as well as industrial practitioners $[29,30]$.

They can stimulate the development of new approaches in design, production, and service, eventually leading to more innovations, such as better data management in order to improve the production process and performance and to ensure continuity and traceability of information [31], support for the analysis of production-line performance parameters, allowing for continuous monitoring of the line balancing and performance with the variations in the production demand [32], and support for monitoring and decision making regarding the ergonomic performance of manual production lines [33].

\section{Methodology}

Review studies can be of several types. In this study, a combination of bibliometric and systematic reviews is adopted. Bibliometric analyses are extensively performed to trace the knowledge anatomy of a research field and are used to analyze research topics [34]. Systematic literature reviews are used to synthesize the contents of the literature, limit bias [35], and identify possible research gaps.

For the purpose of answering RQ1 and RQ2 and identifying the publication trends and most influential research themes, two bibliometric analyses were performed, which provided comprehensive maps of the knowledge structures of the DT research field and the intersection between the DT and safety research fields. The results from the clustering of the intersection between the DT and safety research fields provided a foundation for a cluster content analysis aimed at answering RQ3 and identifying the recent research trends in the domain, as well as the gaps and areas for future research. Figure 3 proposes a schematization of the adopted methodology.

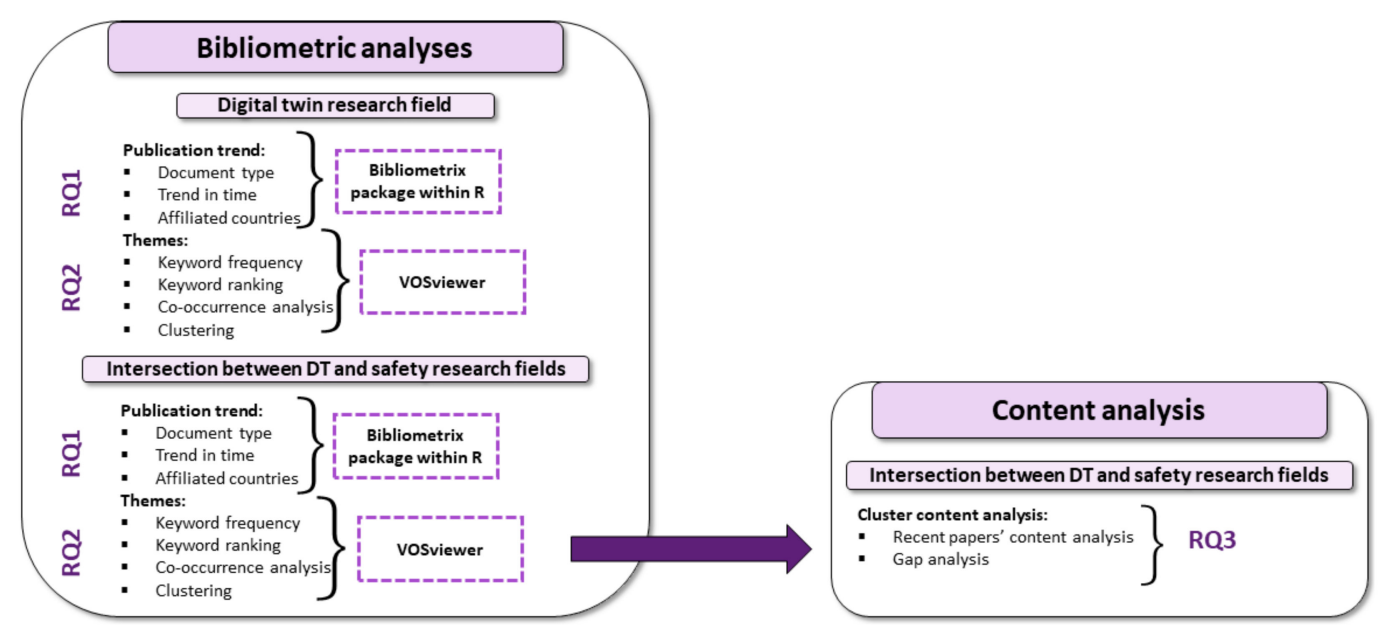

Figure 3. Methodological framework.

\subsection{Search Protocol and Datasets}

The Scopus database, the widest repository of peer-reviewed scientific literature, was used for the construction of the datasets. The first step was the identification of the keywords to be used for the selection of the document samples.

The terms selected to extract the document sample for the first bibliometric analysis (Figure 3) were the following: (i) digital; (ii) twin. Scopus was queried on 10 February 
2021 with this combination of keywords: "digital AND twin". This choice allowed the borders of the analysis to be defined, ensuring a specific focus on the topics to be inspected. The extraction from the Scopus database was limited to: (i) studies written in the English language; (ii) the "Engineering" and "Computer science" areas; (iii) the period 2003-2021 because the first theorization of DTs was provided by Grieves in 2003. It provided an output of 3301 documents, whose citation information (authors, documents title, publication year), abstract, and index keywords were exported.

In order to limit the analysis to the intersection between the digital twin and safety management topics, a second extraction from the Scopus database was performed to obtain the document sample for the second bibliometric analysis (Figure 3). For the same time period, 2003-2021, Scopus was queried on 10 February, 2021 with the combination of keywords "digital AND twin AND safety", and with the same limitations as in the first bibliometric analysis. The obtained dataset consisted of 190 documents, whose citation information (authors, documents title, publication year), abstract, and index keywords were exported.

\subsection{Bibliometric and Content Analysis Methods}

The methodology adopted to investigate the scientific literature dynamics related to the two document samples extracted from Scopus was based on the use of two types of software for bibliometric analysis. The Bibliometrix package application in the R software was used to evaluate the growth, maps, and trends of the scientific field of research [36], while VOSviewer 1.6.14, which was developed to conduct text mining and to construct bibliometric maps [37], was used to identify the study keywords' co-occurrence.

In the study, the VOSviewer software was used to create a network map of the cooccurrence of terms considering index keywords. The keywords' co-occurrence analysis was carried out using the full counting method. The relatedness of items was determined based on the number of documents in which they occurred together.

According to the methods proposed by Donohue [38], the cut-off point for the term occurrence was determined with the following Formula (1):

$$
T=(1+\sqrt{1+8 \times I}) / 2
$$

where $T$ represents the optimal minimum number of occurrences of a keyword and $I$ is the total number of keywords. Notwithstanding, to ensure wider software processing, keywords that co-occurred at least 10 times were selected for the analysis [39].

The index keywords were processed using VOSviewer, and the results were displayed in the network visualization and the overlay visualization. The network visualization shows keyword co-occurrence, where the dimensions of circles represent the weights of keywords, the lines represent the ways in which two words are linked, and thicker lines mean stronger connections among words. In the network visualization, VOSviewer uses colors to indicate the cluster to which a keyword has been assigned. The clustering technique [40] requires an algorithm for solving an optimization problem. For this purpose, VOSviewer implements the smart local moving algorithm introduced by Waltman and Van Eck [41].

The overlay visualization replicates the same map as that in the network visualization, but with different colors. The items and their links are colored in order to make it possible to view temporal trends and to identify which keywords were used most frequently during the observation period. The layout of the map was built by normalizing the strengths of the links among the elements through the association strength method according to Van Eck and Waltman [42].

In order to conduct a systematic review of the safety management issues related to the DT concept, documents were extracted from the clusters obtained through the second bibliometric phase. The most recent documents were carefully examined to identify the common features that characterized each cluster as well as the gaps in the literature. 


\section{Results}

\subsection{The Digital Twin Research Field}

Conference papers represent essential documents for supporting the scientific development of new research and application fields. As shown in Figure 4, the analysis of the dataset according to the type of document shows that the majority are conference papers $(57 \%)$, followed by journal articles $(33 \%)$, conference reviews $(4 \%)$, and book chapters $(3 \%)$. These results represent important evidence that allows Digital Twin research to be identified as an emerging research field.

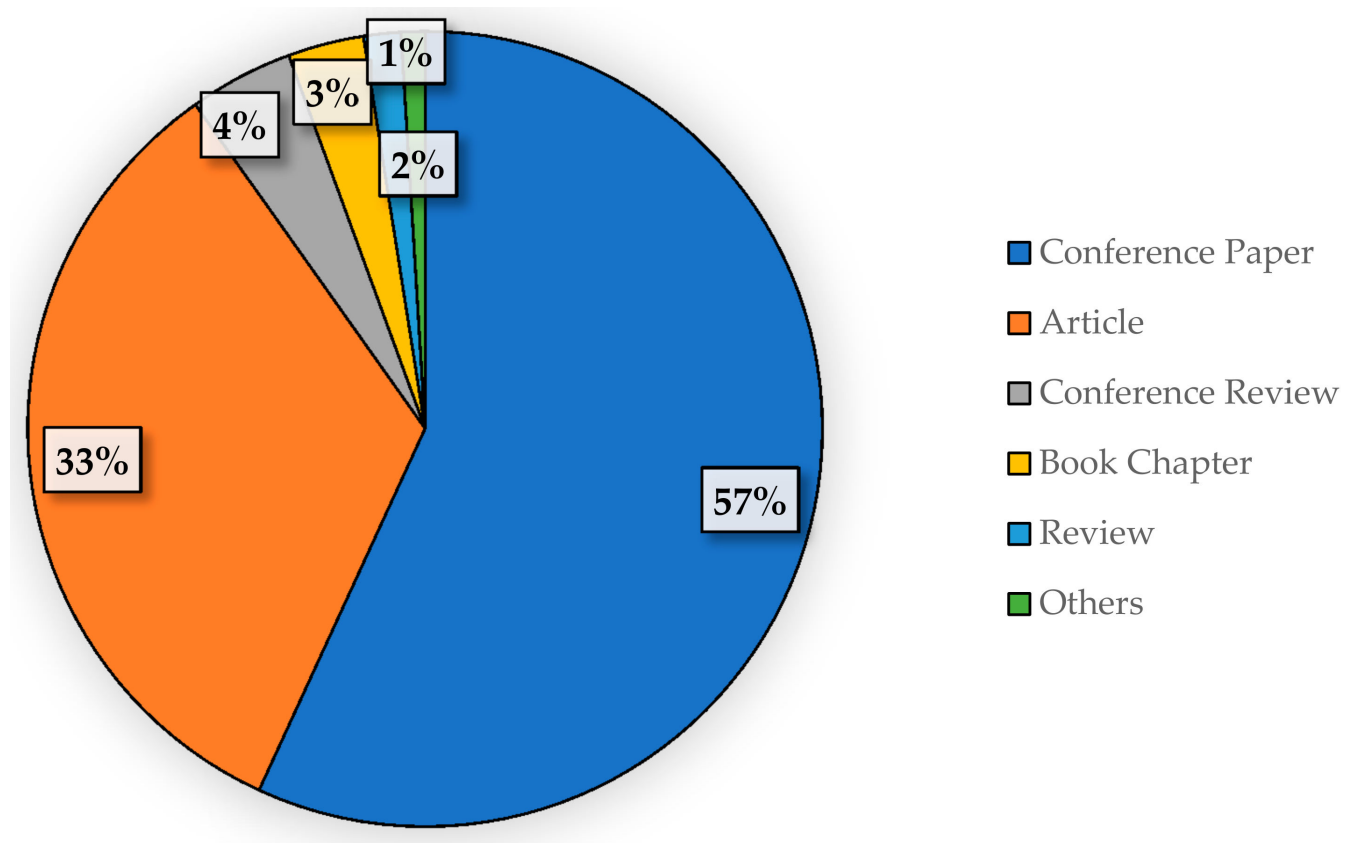

Figure 4. Publications in the DT research field by document type.

Figure 5 illustrates the progression of publications available in the Scopus data on Digital Twins in the period 2003-2021. There was an upsurge in publications from just 25 documents published in 2003 to 1279 documents in 2020. Research on Digital Twins saw a sudden spurt from 2017, which could represent a point of discontinuity, with an exponential shape in the last three years (2018-2020). The main reason for this surge may mainly be attributed to the governmental ICT (Information and Communication Technologies) investments in many countries carried out by the adoption of Industry 4.0 policy plans [43]. Even if there are more conference papers than journal articles in absolute terms, in the last three years (2018-2020), the share of journal articles over the total published documents regarding DTs has increased noticeably, going from $24 \%$ to $35 \%$, registering an opposite trend compared to conference papers, which fell from $67 \%$ to $52 \%$.

Table 1 lists the top countries affiliated with authors of DT research, with the leading three being Germany (492 documents), the United States (477 documents), and China (434 documents). They are the top three global manufacturing export countries in the world [44], and Germany, in addition to having a leading position in Europe (Figure 6), is the country where the Industry 4.0 concept was first developed [44,45]. A noticeable selfperpetuating effect of giving and taking references was observed in these countries, which register more study contributions to the pool of the DT field. Countries that registered a high production were also among the countries whose studies received more citations. It can be said that the most well-established countries are dominating or leading in the field, and this can also be seen in the citation patterns. 


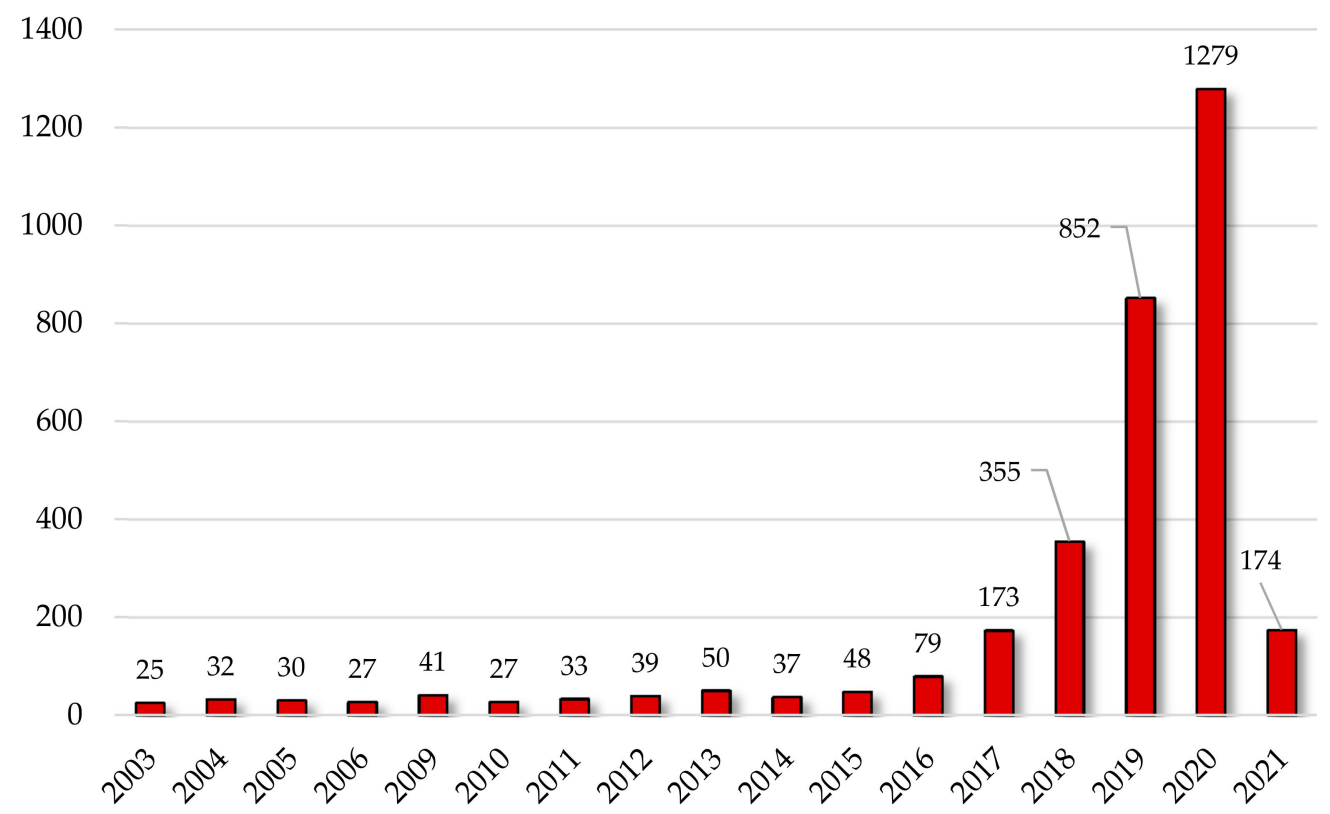

Figure 5. Annual publication trend of 3301 documents retrieved from Scopus for the DT research field in the period 2003-2021.

Table 1. Top ten affiliated countries publishing on DTs.

\begin{tabular}{cc}
\hline Country & Number of Documents \\
\hline Germany & 492 \\
United States & 477 \\
China & 434 \\
United Kingdom & 241 \\
Russian Federation & 205 \\
Italy & 164 \\
France & 144 \\
India & 116 \\
Spain & 95 \\
South Korea & 89 \\
\hline
\end{tabular}

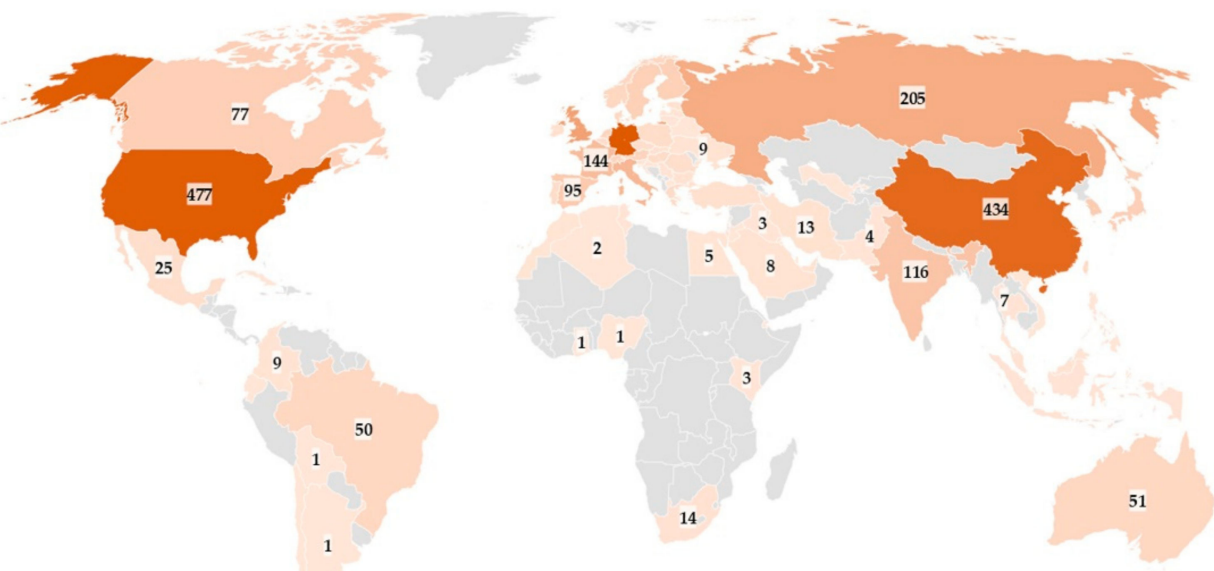

Figure 6. Map of affiliated countries publishing on DTs. 
Keyword analysis was performed to explore the most prevalent themes in the DT research field. A total of 15,901 keywords were identified in 3301 documents. It is important to evaluate the keywords of a document to understand how authors frame their work, what the most interesting aspect of the research is or how it is evolving, and what trends are being created. From the extracted document sample, a count of the index keywords was performed in order to calculate their frequency and rank them. Table 2 shows the ranking of the top ten most relevant Keywords-Plus (ID). The ID is standardized; it is defined by Scopus to help in the research of documents associated with a topic. "Digital twin" is the most frequently used keyword, with 1404 occurrences, which indicates that this word alone is used as a termed concept in the literature. The other most frequently used keywords are "life cycle" (333 occurrences), "manufacture" (325 occurrences), "embedded systems" (248 occurrences), "Internet of Things" (206 occurrences), and "Industry 4.0" (200 occurrences).

Table 2. Top ten most frequent index keywords in the DT research field.

\begin{tabular}{cc}
\hline Keyword & Frequency \\
\hline Digital twin & 1404 \\
Life cycle & 333 \\
Manufacture & 325 \\
Embedded systems & 248 \\
Internet of things & 206 \\
Industry 4.0 & 200 \\
Decision making & 179 \\
Cyber-physical system & 169 \\
Virtual reality & 153 \\
Digital storage & 151 \\
\hline
\end{tabular}

Based on the hypothesis that a research specialty can be identified by the relations among document keywords, keyword co-occurrence analysis is useful for identifying the thematic areas or clusters that constitute the theoretical blocks or foundational topics of the field under analysis [46].

Starting from the entire document sample, including 15,901 keywords, a co-occurring keyword analysis was performed in order to construct diagrams to display the network and the overlay visualization (respectively, Figures 7 and 8). Considering keywords that co-occurred at least 10 times, 502 keywords were selected for the final analysis.

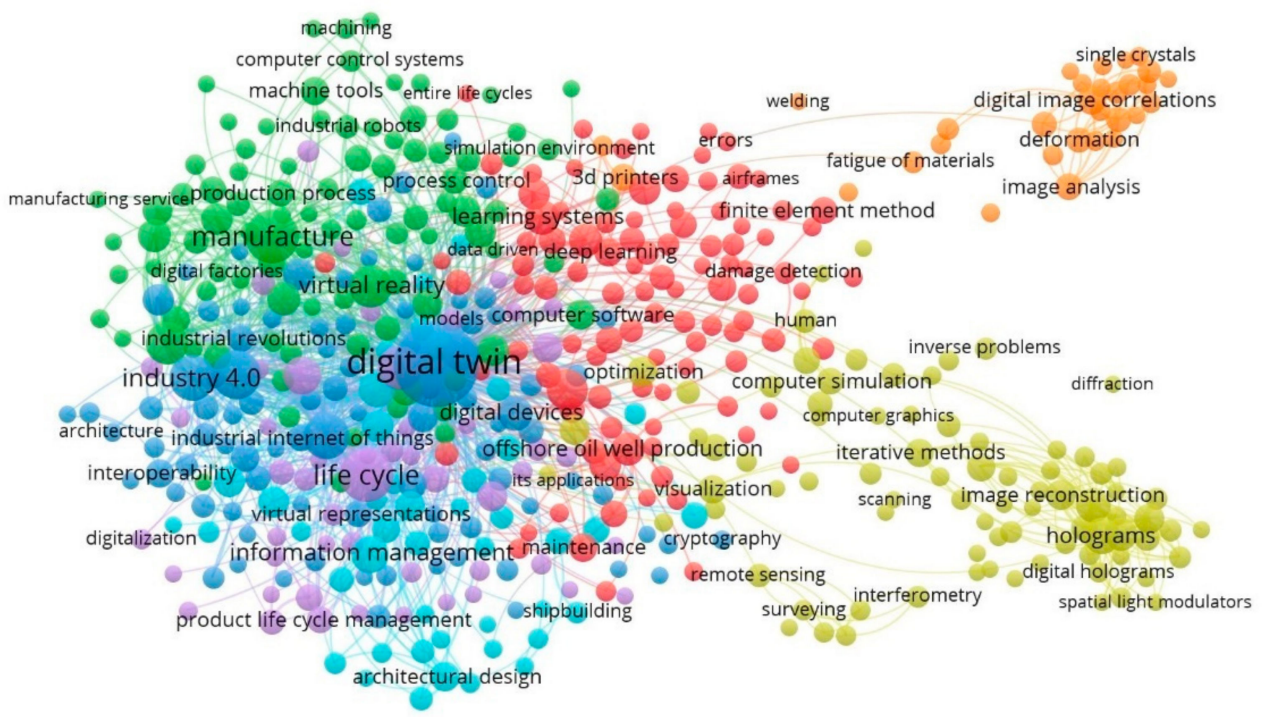

Figure 7. Network visualization of the DT research field. 


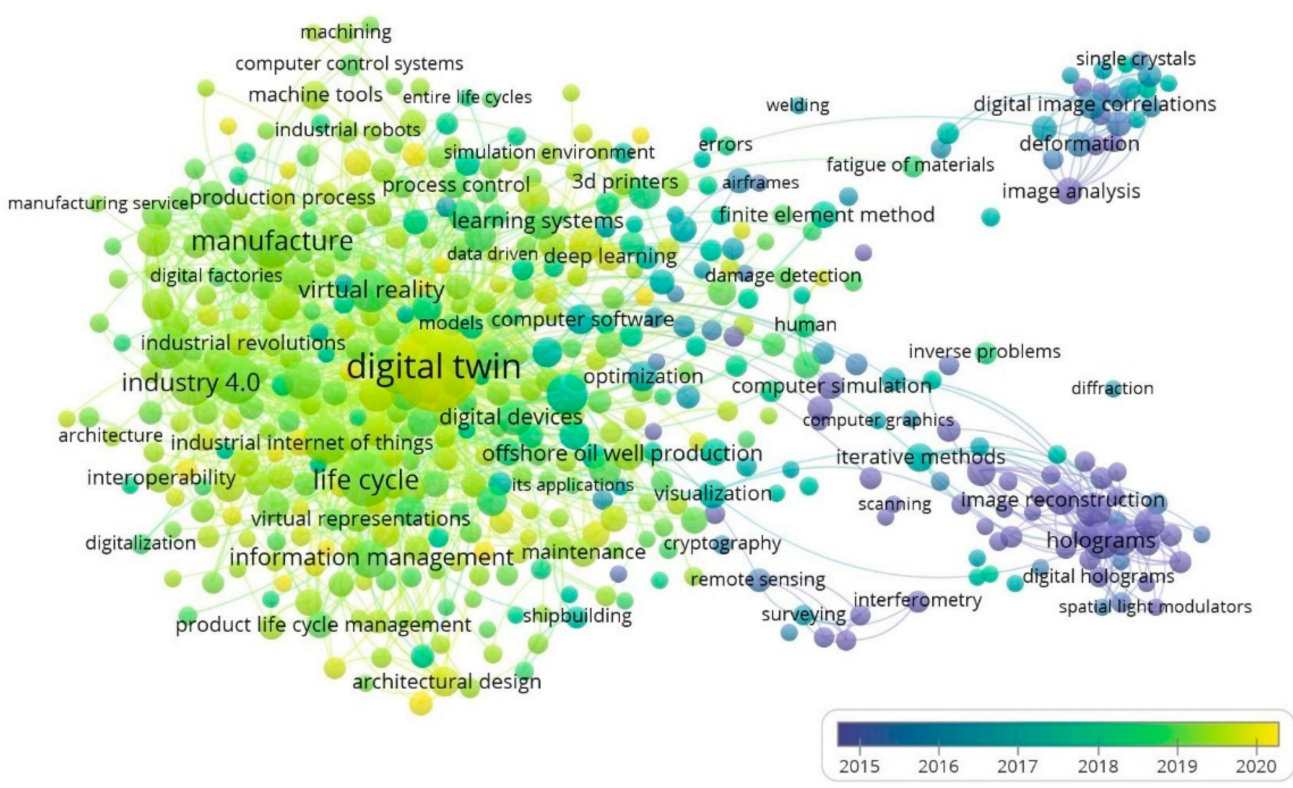

Figure 8. Overlay visualization of the DT research field.

The keywords were grouped into clusters, represented by different colors. In particular, the keywords were clustered into seven groups, and each keyword was assigned to only one cluster. As shown by the network visualization (Figure 7), the DT research field is primarily composed of seven clusters of connected topics: Industry 4.0 and IoT (clusterblue), learning systems (cluster-red), smart manufacturing (cluster-green), information management (cluster—cyan), life-cycle management (cluster-purple), holograms (clusteryellow), and digital image analysis (cluster-orange).

A very close linkage between five clusters (red, blue, green, purple, and cyan) is clearly observable, while two clusters appear disconnected from the first ones (yellow and orange).

The clusters clearly indicate that scientific research in the field of DTs has focused, above all, on Industry 4.0 manufacturing, life-cycle management, and data processing and analysis. Since it is evident that the orange and yellow clusters are almost totally unlinked from each other, the holograms and digital image analysis research fields can be considered to have developed almost autonomously.

In the overlay visualization, which shows the temporal distribution of the keywords in each cluster (Figure 8), keywords are colored according to a score. This score is given based on the average year of occurrence of a keyword. Colors range from blue (oldest time period) to green and yellow (most recent time periods). It emerged that the topics related to holograms (cluster-yellow) and digital image analysis (cluster-orange) were developed before the others. This could mean that in an early stage, the DT concept and research field derived previously from holograms, digital image analysis, and scanning, and then evolved to a wider and more common application that is usually adopted in manufacturing activities.

The most recent documents in the scientific literature refer, in fact, to the fields of smart manufacturing, IoT, life cycle, and information management (Figure 8), which also represent the main research fields according to the co-occurrence network map (Figure 7). The latter are trendy topics. Within them, there are a series of strongly linked research sub-fields, e.g., quality control of processes and products, design of processes and products, predictive analysis through machine learning algorithms, and, finally, safety management.

\subsection{Bibliometric Results on the Intersection between the DT and Safety Research Fields}

Safety aspects are fundamental within the manufacturing sector and represent a research field with great potential and wide application areas [47]. As indicated in Section 3, 
the linkages between the Digital Twin and safety issues were investigated through a second bibliometric analysis.

As for the document sample related to Digital Twins, the document sample related to studies that integrate the DT and safety research fields also includes many conference proceedings. The latter generally report preliminary studies, which serve as a basis for the development of more complex research activities that later conclude with international journal publication [48]. Figure 9 shows that conference papers represent $65 \%$ of the dataset according to the type of document, followed by journal articles (33\%), conference reviews $(7 \%)$, reviews $(4 \%)$, and book chapters $(1 \%)$. In the light of these results, studies that integrate DTs and safety issues can be considered as the most recent emerging research field within the wider research field of DTs [49].

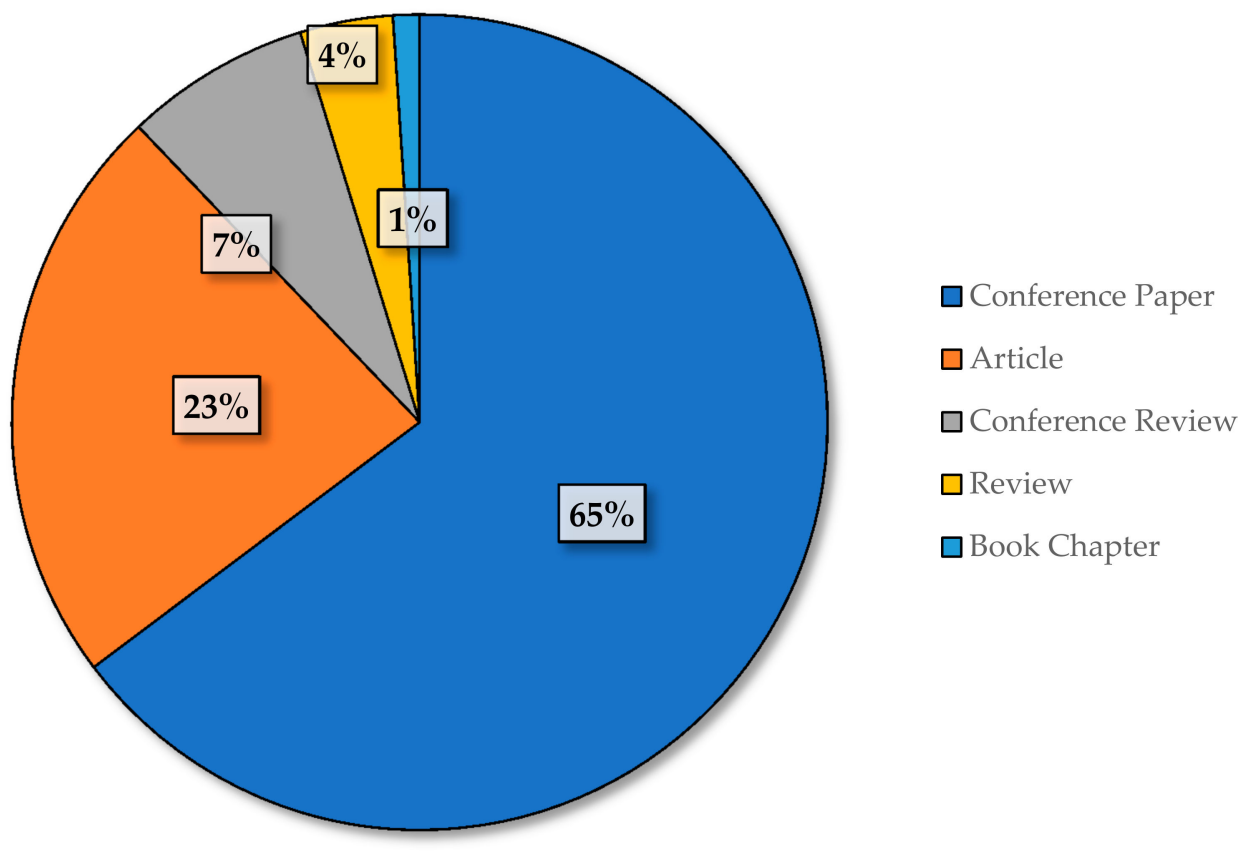

Figure 9. Publications in the intersection of the DT and safety research fields by document type.

Figure 10 highlights the trend of publications available in the Scopus data on the intersection between the Digital Twin and safety research fields in the period 2003-2021. Most of the articles were published in the three-year period of 2018-2020. In fact, there was, an exponential increase in publications from 0 documents published in 2003 to 92 documents in 2020, which represents a peak, confirming the researchers' pioneering interest in developing the scientific topics of Digital Twins related to process manufacturing activities and, consequently, to safety management.

Table 3 lists the top countries affiliated with the authors of research on the intersection of DTs and safety, with the leading three being the United States (40 documents), Germany (25 documents), and China (21 documents), confirming the rank results registered for the DT research field, with the only permutation being between Germany and the United States. The numbers of documents published by authors from the UK (16 documents) and Italy (13 documents) are also noteworthy. Italy earned the fifth position, also highlighting the role that the national "Industry 4.0" plan played in driving organizational changes in enterprises that particularly addressed safety issues [50]. Figure 11 shows Map of affiliated countries publishing in the intersection of the DT and safety research fields. Even if they are not very numerous, documents from Italy register a high impact on the research field. As an example, the review conducted by Cimino et al. [51] (2019) of the Politecnico di Milano, which was published in Computers in Industry and dealt with a topic related to the intersection between DTs and safety, is among the most cited documents (43 citations). This highly cited document is followed by the study by Oyekan et al. [52] (34 citations), 
which shows how virtual reality Digital Twins could assist in the safe implementation of human-robot collaborative strategies in factories of the future.

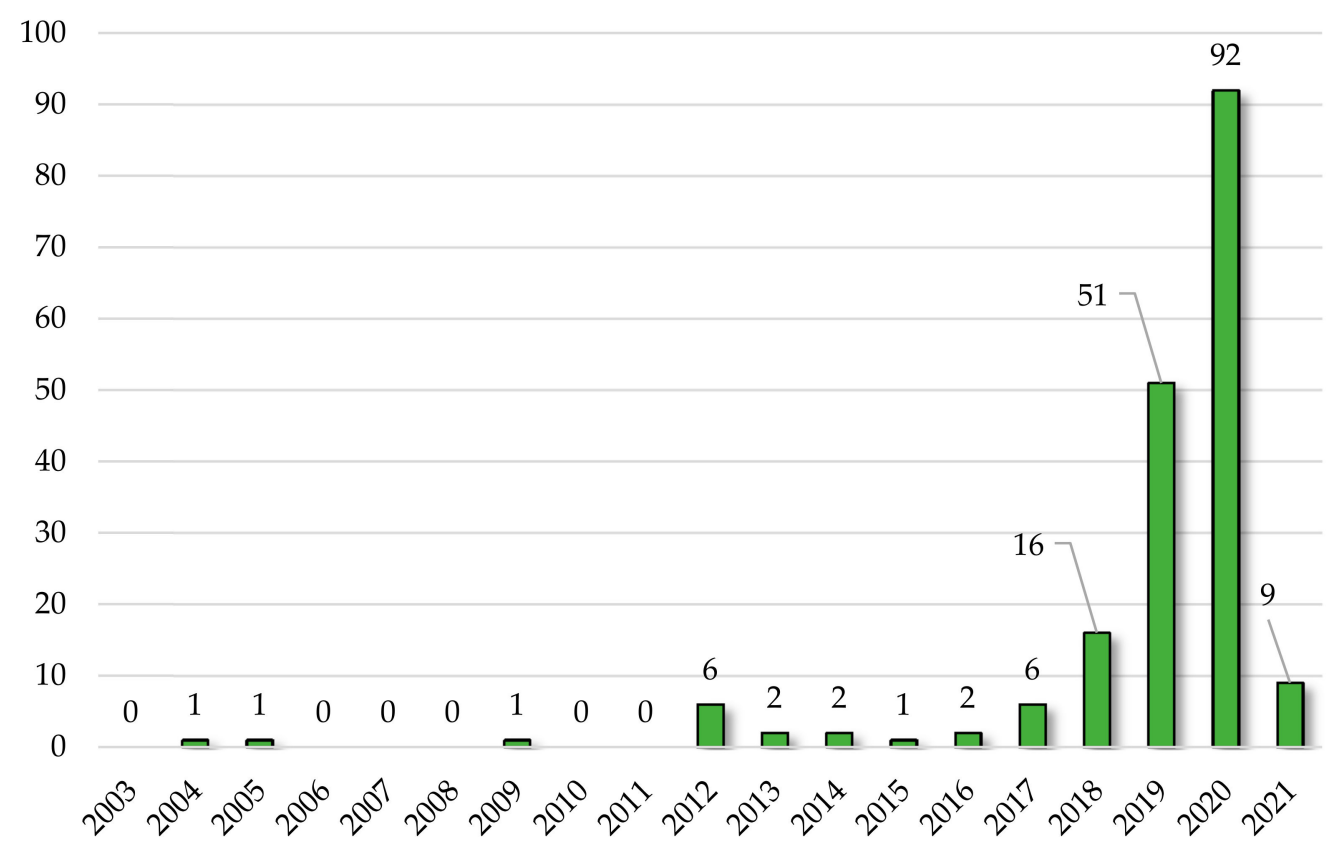

Figure 10. Annual publication trend of 3301 documents retrieved from Scopus for the intersection between the DT and safety research fields in the period 2003-2021.

Table 3. Top ten affiliated countries publishing in the intersection of the DT and safety research fields.

\begin{tabular}{cc}
\hline Country & Number of Documents \\
\hline United States & 40 \\
Germany & 25 \\
China & 21 \\
United Kingdom & 16 \\
Italy & 13 \\
Russian Federation & 10 \\
Austria & 9 \\
Sweden & 8 \\
India & 7 \\
Norway & 6 \\
\hline
\end{tabular}

Keyword analysis was performed to explore the most prevalent themes in the intersection between the DT and safety research fields. A total of 1673 keywords were identified in 190 documents. From the extracted document sample, a count of the index keywords was performed in order to calculate their frequency and to rank them. Table 4 shows the ranking of the top ten most relevant Keywords-Plus (ID). As for the first bibliometric analysis, "Digital twin" is the most frequently used keyword, with 93 occurrences, followed by "life cycle" (32 occurrences), "safety engineering" (21 occurrences), "accident prevention" (19 occurrences), and "virtual reality" (19 occurrences).

A significant finding outlined by the keyword analysis is that there are themes that occur in both the DT research field and the intersection of the DT and safety research fields. This circumstance highlights the unanimity on the conceptualization of the Digital Twin and its applications, as well as the mostly indirect and diversified references to safety aspects in much of the scientific literature on DTs. 


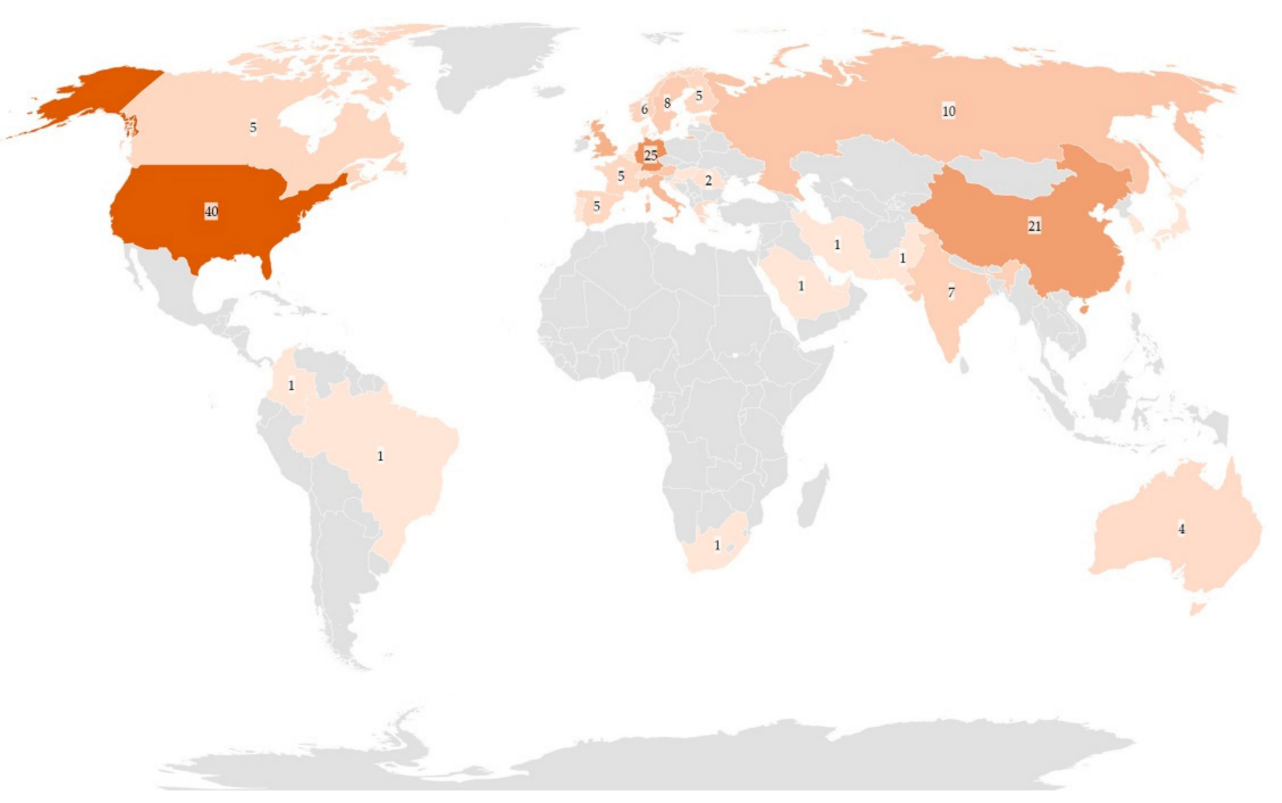

Figure 11. Map of affiliated countries publishing in the intersection of the DT and safety research fields.

Table 4. Top ten most frequent index keywords in intersection of the DT and safety research fields.

\begin{tabular}{cc}
\hline Keyword & Frequency \\
\hline Digital twin & 93 \\
Life cycle & 32 \\
Safety engineering & 21 \\
Accident prevention & 19 \\
Virtual reality & 19 \\
Internet of Things & 17 \\
Embedded systems & 17 \\
Manufacture & 16 \\
Offshore oil well production & 12 \\
Offshore technology & 10 \\
\hline
\end{tabular}

Starting from the document sample, which included 1673 keywords, a co-occurring keyword analysis was performed in order to obtain Figures 12 and 13, which display the network and the overlay visualization for the intersection between the DT and safety research fields, respectively. In this case, 51 keywords were selected for the analysis, since they co-occurred at least 10 times.

As shown in Figure 12, the research field derived from the intersection between DTs and safety consists of seven clusters: decision making and offshore applications (clusterred), IoT and life-cycle approaches (cluster-green), Industry 4.0: from manufacture to virtual reality (cluster-blue), machine learning support for DTs and safety (cluster-yellow), safety engineering (cluster-purple), hazards and risk assessment (cluster-orange), and DTs in battery management systems (cluster-cyan).

In the overlay visualization, which shows the temporal distribution of the keywords in each cluster (Figure 13), the field of studies regarding the intersection between DTs and safety has evolved from a previous concentration on topics related to aircraft and fleet operations to wider issues related to accident prevention and risk and information management, as well as to more strategic and specific themes referring to life-cycle management and offshore technology applications. 


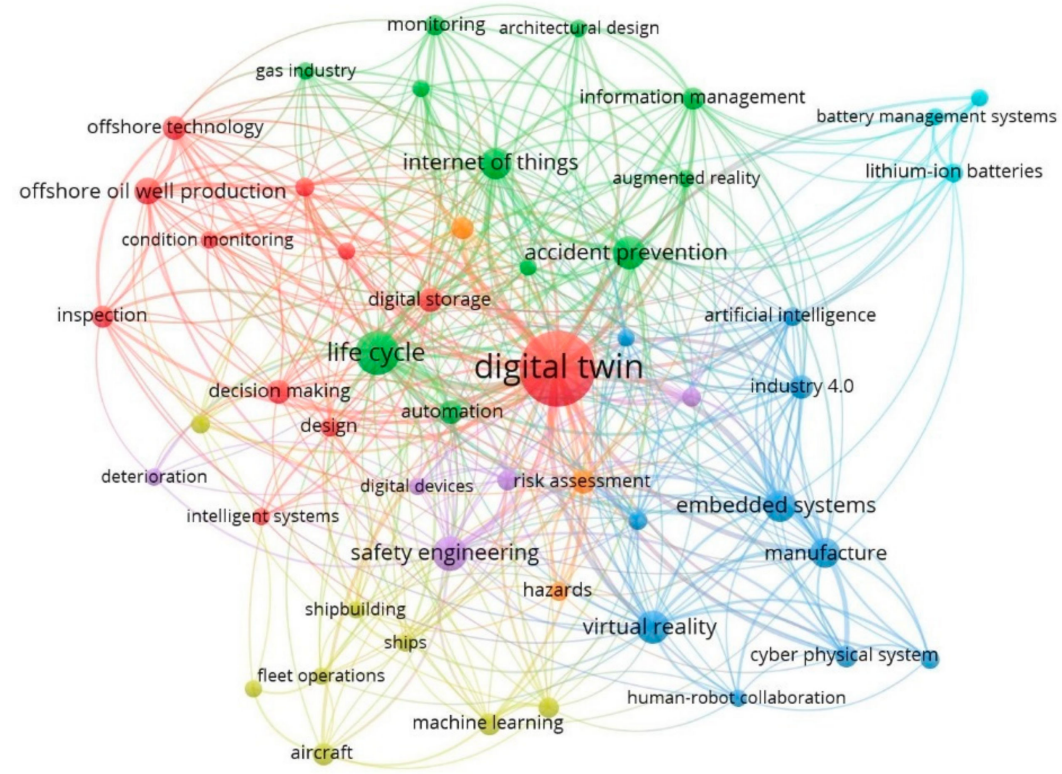

Figure 12. Network visualization of the intersection of the DT and safety research fields.

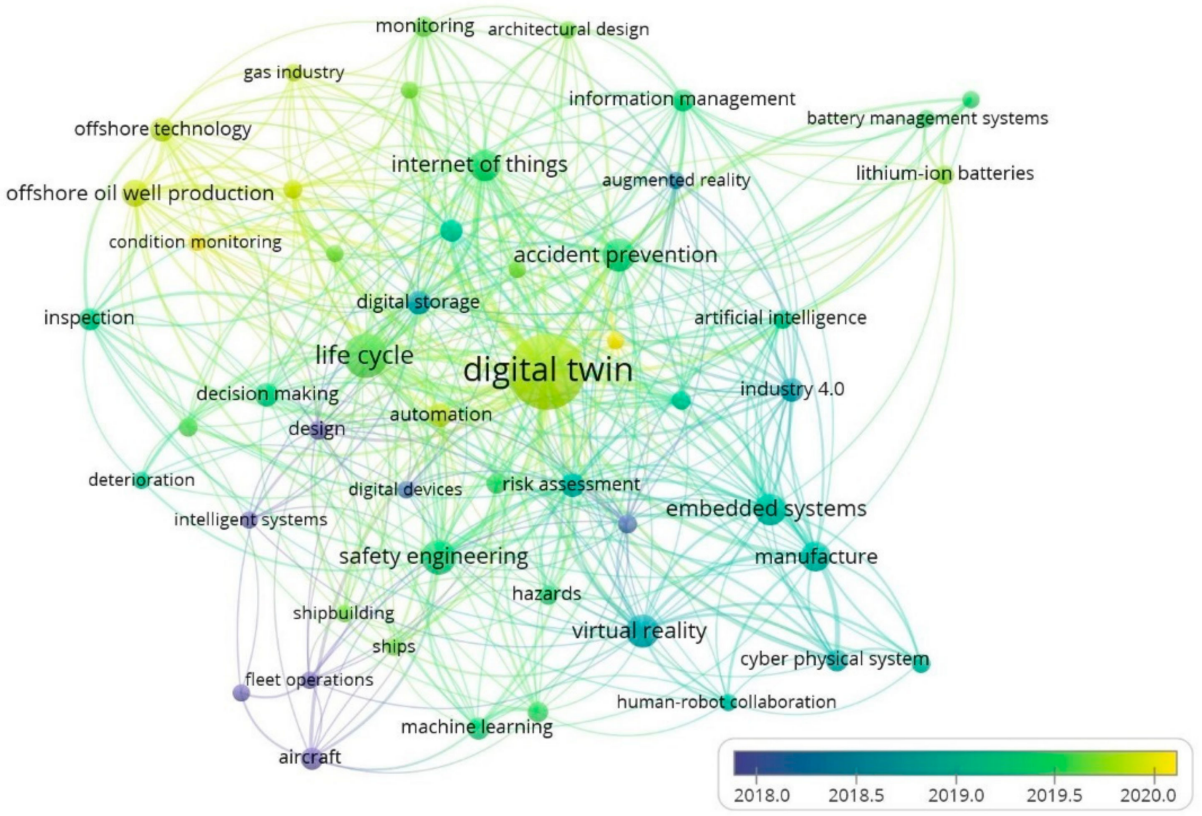

Figure 13. Overlay visualization of the intersection of the DT and safety research fields.

\subsection{Cluster Content Results for the Intersection between the DT and Safety Research Fields}

As shown in Figure 12, VOSviewer uses colors to indicate the cluster to which a keyword has been assigned within the network visualization based on the methods explained in Section 3.2.

The red cluster of keywords, called "Decision making and offshore applications", includes studies regarding DT solutions aimed at supporting decision-making processes. These studies identify the Digital Twin concept as a promising tool for decision makers and stakeholders alike, which is bound to benefit those who use it [53]. In particular, DTs solve big data problems in the field of offshore resources, letting workers spend less time looking for data and more time identifying trends and innovative ways to exploit the data, e.g., smarter drilling, greater field automation, or improved safety [54]. Based on in situ measurement information, DTs can support operational and maintenance decisions that will preserve the integrity, safety, and availability of assets [55]. 
The green cluster, called "IoT and life-cycle approaches", regards studies that consider that a DT should encompass and plan the entire life cycle of a physical asset, thus producing profound differences depending on the application domain [56]. Through the use of the IoT, the gap between the physical and virtual worlds is filled by bridging a physical component's sensors and actuators with its digital counterpart [57]. In the safety domain, a DT provides an opportunity to train employees in virtual environments, thus helping to achieve accident prevention and to reduce the probability of accidents that may occur during on-the-job training [58].

The blue cluster, called "Industry 4.0: from manufacture to virtual reality", groups the latest research related to Digital Twins and virtual reality environments for safety purposes within the Industry 4.0 paradigm. Over recent years, the concept of humanmachine interaction has received wide attention, since it represents the basis for achieving automation in manufacturing. Conventional simulations do not allow us to experience future production systems as end-users in an immersive environment. For this reason, virtual reality has had technological development [59]. Cyber-physical systems, however, require operators' awareness of the situation in order to be able to adequately address potential issues in a timely manner. Detecting early symptoms may speed up the incident response process and mitigate the consequences of business interruption or safety hazards. Running parallel to their physical counterparts, DTs allow for the deep inspection of their behavior without the risk of disrupting operational technology processes [60].

The yellow cluster, called "Machine learning support for DT and safety", includes studies that use machine learning algorithms to rapidly ascertain optimal aircraft dynamics to maximize the fire-retardant release effectiveness [61], to create a digital representation of humans that focuses on their vital quantities, as well as on the surrounding environment, for health monitoring purposes [62], or to enable industrial robots to bypass obstacles or people in a workspace [63].

The purple cluster, called "Safety engineering", regards studies about the interactions among DT data acquisition, DT data processing, and safety issues [49], as well as research regarding advanced structural simulations combined with physics-based deterioration models in order to calculate structural performance [64].

The orange cluster, called "Hazards and risk assessment", groups studies about risk assessment and tools of risk prediction. By comparing the real data with those obtained by the simulation software, DTs can predict risks and/or anomalies and communicate with a server in order to generate a warning [65]. This is particularly relevant when DTs serve to audit and evaluate compliance with legal requirements in everyday production and logistics processes. Non-compliance can endanger employees and the environment, and can cause financial and reputational damage [66].

The cyan cluster, called "DT in battery management systems", refers to studies that aim to enhance the safety, reliability, and performance of battery systems. All data relevant to batteries can be measured and transmitted to create a Digital Twin of a battery system, allowing for the diagnostic evaluation of a battery's charge and aging level [67].

As highlighted through the cluster content analysis, the scientific literature lacks a generic and widely recognized DT architecture. This heterogeneity unavoidably requires a deeper understanding of how to deal with DT systems by evaluating and comparing them and exploring how they differ in handling different environments. The lack of standardization and the variety of DT definitions, which cause discrepancies among DT implementation projects, represent a challenge that requires further research efforts aimed at fastening the progress in supporting safety management.

When trying to address open research questions in the field of Digital Twins, another challenge comes from the multidisciplinary approaches needed to design and develop adequate safety management measures. With technological improvements and the spread of blockchain, the scientific gap related to the integration of data for small IoT systems, as well as large heterogeneous systems, including human interaction, should be filled. 


\section{Conclusions}

The Digital Twin technology is an emerging topic that has captured the attention of researchers in recent years. It is also becoming popular amongst managers and practitioners, thus demonstrating that it is one of the most fertile and contributing fields in the areas of engineering and computer science research.

This review further contributes to DT research in terms of unfolding the evolving literature in terms various themes and trends, hence putting forth the status of scholarly work since its inception in 2003. However, some gaps in the research on the intersection between the DT and safety research fields have been identified, and recent research efforts were addressed.

With the intention of thoroughly reviewing the existing literature, this study provides valuable insights into DTs and safety. Such concepts have an ever-increasing importance in day-to-day management decisions. The scholarly work reveals the still scarce implementation of DT technologies across industry, and specifically for safety management purposes. This study represents a wake-up call for decision makers and other stakeholders who should undertake paths towards improvements enabled by DT technologies and, ultimately, safety in its complex definition. There is a large scope of contributions to theoretical development, methodologies, and new applications. DT technology is an issue with vast implications for safety management, and its development can guide the way to competitive and stable industries.

Author Contributions: Conceptualization, G.P.A. and M.G.G.; Data curation, G.P.A.; Methodology, G.P.A., M.G.G., and V.E.; Supervision, M.G.G.; Validation, G.P.A.; Visualization, G.P.A.; Writingoriginal draft, M.G.G., G.P.A., and V.E.; Writing — review and editing, M.G.G. and V.E. All authors have read and agreed to the published version of the manuscript.

Funding: This research is part of the activities carried out within SO4SIMS project (Smart Operators 4.0 based on Simulation for Industry and Manufacturing Systems) funded by the Italian Ministry of Education, Universities and Research MIUR (Project PRIN-2017FW8BB4).

Institutional Review Board Statement: Not applicable.

Informed Consent Statement: Not applicable.

Conflicts of Interest: The authors declare no conflict of interest.

\section{References}

1. Jacoby, M.; Usländer, T. Digital Twin and Internet of Things—Current Standards Landscape. Appl. Sci. 2020, 10, 6519. [CrossRef]

2. Culot, G.; Nassimbeni, G.; Orzes, G.; Sartor, M. Behind the definition of Industry 4.0. Analysis and open questions. Int. J. Prod. Econ. 2020, 226, 107617. [CrossRef]

3. Turel, M.; Akis, E. Industry 4.0 and Competitiveness. Res. J. Bus. Manag. 2019, 6, 204-212. [CrossRef]

4. Florescu, A.; Barabaș, S.A. Modeling and Simulation of a Flexible Manufacturing System-A Basic Component of Industry 4.0. Appl. Sci. 2020, 10, 8300. [CrossRef]

5. Lezzi, M.; Lazoi, M.; Corallo, A. Cybersecurity for Industry 4.0 in the current literature: A reference framework. Comput. Ind. 2018, 103, 97-110. [CrossRef]

6. Negri, E.; Fumagalli, L.; Macchi, M. A review of the roles of digital twin in CPS-based production systems. Procedia Manuf. 2017, 11, 939-948. [CrossRef]

7. De Miranda, S.S.-F.; Aguayo-González, F.; Salguero-Gómez, J.; Ávila-Gutiérrez, M.J. Life cycle engineering 4.0: A proposal to conceive manufacturing systems for industry 4.0 centred on the human factor (DfHFinI4. 0). Appl. Sci. 2020, 10, 4442. [CrossRef]

8. Wang, X.; Ong, S.K.; Nee, A.Y.C. A comprehensive survey of augmented reality assembly research. Adv. Manuf. 2016, 4, 1-22. [CrossRef]

9. Khalek, I.A.; Chalhoub, J.M.; Ayer, S.K. Augmented reality for identifying maintainability concerns during design. Adv. Civ. Eng. 2019, 3, 8547928. [CrossRef]

10. Li, Y.; Guldenmund, F.W. Safety management systems: A broad overview of the literature. Saf. Sci. 2018, 103, 94-123. [CrossRef]

11. Huang, L.; Wu, C.; Wang, B.; Ouyang, Q. Big-data-driven safety decision-making: A conceptual framework and its influencing factors. Saf. Sci. 2018, 109, 46-56. [CrossRef]

12. Gobbo, J.A., Jr.; Busso, C.M.; Gobbo, S.C.O.; Carreão, H. Making the links among environmental protection, process safety, and industry 4.0. Process Saf. Environ. Prot. 2018, 117, 372-382. [CrossRef] 
13. Huang, L.; Wu, C.; Wang, B. Challenges, opportunities and paradigm of applying big data to production safety management: From a theoretical perspective. J. Clean. Prod. 2019, 231, 592-599. [CrossRef]

14. Wang, B.; Wu, C.; Huang, L.; Kang, L. Using data-driven safety decision-making to realize smart safety management in the era of big data: A theoretical perspective on basic questions and their answers. J. Clean. Prod. 2019, 210, 1595-1604. [CrossRef]

15. Lee, J.; Cameron, I.; Hassall, M. Improving process safety: What roles for Digitalization and Industry 4.0? Process Saf. Environ. Prot. 2019, 132, 325-339. [CrossRef]

16. Wang, B. Safety intelligence as an essential perspective for safety management in the era of Safety 4.0: From a theoretical to a practical framework. Process Saf. Environ. Prot. 2021, 148, 189-199. [CrossRef]

17. Gattullo, M.; Scurati, G.W.; Evangelista, A.; Ferrise, F.; Fiorentino, M.; Uva, A.E. Informing the use of visual assets in industrial augmented reality. In Proceedings of the International Conference on Design Tools and Methods in Industrial Engineering, Modena, Italy, 9-10 September 2020.

18. Martinettia, A.; Rajabalinejada, M.; van Dongena, L. Shaping the future maintenance operations: Reflections on the adoptions of augmented reality through problems and opportunities. Procedia CIRP 2017, 59, 4-17. [CrossRef]

19. Siew, C.Y.; Ong, S.K.; Nee, A.Y.C. Improving maintenance efficiency and safety through a human-centric approach. Adv. Manuf. 2021, 9, 104-114. [CrossRef]

20. Grieves, M.W. Product lifecycle management: The new paradigm for enterprises. Int. J. Prod. Dev. 2005, 2, 71-84. [CrossRef]

21. Shafto, M.; Conroy, M.; Doyle, R.; Glaessgen, E.; Kemp, C.; LeMoigne, J.; Wang, L. Modeling, Simulation, Information Technology E Processing Roadmap; National Aeronautics and Space Administration: Washington, DC, USA, 2012.

22. Boschert, S.; Rosen, R. Digital twin-The simulation aspect. In Mechatronic Futures; Hehenberger, P., Bradley, D., Eds.; Springer: Cham, Switzerland, 2016; pp. 59-74. [CrossRef]

23. Lee, J.; Lapira, E.; Bagheri, B.; Kao, H.A. Recent advances and trends in predictive manufacturing systems in big data environment. Manuf. Lett. 2013, 1, 38-41. [CrossRef]

24. Rosen, R.; Von Wichert, G.; Lo, G.; Bettenhausen, K.D. About the importance of autonomy and digital twins for the future of manufacturing. IFAC PapersOnLine 2015, 48, 567-572. [CrossRef]

25. Chen, Y. Integrated and intelligent manufacturing: Perspectives and enablers. Engineering 2017, 3, 588-595. [CrossRef]

26. Zheng, Y.; Yang, S.; Cheng, H. An application framework of digital twin and its case study. J. Ambient Intell. Humaniz. Comput. 2019, 10, 1141-1153. [CrossRef]

27. Vrabič, R.; Erkoyuncu, J.A.; Butala, P.; Roy, R. Digital twins: Understanding the added value of integrated models for through-life engineering services. Procedia Manuf. 2018, 16, 139-146. [CrossRef]

28. Madni, A.M.; Madni, C.C.; Lucero, S.D. Leveraging digital twin technology in model-based systems engineering. Systems 2019, 7, 7. [CrossRef]

29. Tao, F.; Qi, Q.; Wang, L.; Nee, A.Y.C. Digital twins and cyber-physical systems toward smart manufacturing and industry 4.0: Correlation and comparison. Engineering 2019, 5, 653-661. [CrossRef]

30. Tao, F.; Liu, A.; Hu, T.; Nee, A.Y.C. Digital Twin Driven Smart Design; Academic Press: Cambridge, MA, USA, 2020.

31. Pang, T.Y.; Restrepo, J.D.P.; Cheng, C.T.; Yasin, A.; Lim, H.; Miletic, M. Developing a digital twin and digital thread framework for an 'Industry 4.0' Shipyard. Appl. Sci. 2021, 11, 1097. [CrossRef]

32. Fera, M.; Greco, A.; Caterino, M.; Gerbino, S.; Caputo, F.; Macchiaroli, R.; D’Amato, E. Towards digital twin implementation for assessing production line performance and balancing. Sensors 2020, 20, 97. [CrossRef]

33. Greco, A.; Caterino, M.; Fera, M.; Gerbino, S. Digital Twin for Monitoring Ergonomics during Manufacturing Production. Appl. Sci. 2020, 10, 7758. [CrossRef]

34. Merigó, J.M.; Blanco-Mesa, F.; Gil-Lafuente, A.M.; Yager, R.R. Thirty years of the International Journal of Intelligent Systems: A bibliometric review. Int. J. Intell. Syst. 2017, 32, 526-554. [CrossRef]

35. Tranfield, D.; Denyer, D.; Smart, P. Towards a methodology for developing evidence-informed management knowledge by means of systematic review. Br. J. Manag. 2003, 14, 207-222. [CrossRef]

36. Aria, M.; Cuccurullo, C. Bibliometrix: An R-tool for comprehensive science mapping analysis. J. Informetr. 2017, 11, 959-975. [CrossRef]

37. Van Eck, N.J.; Waltman, L. Software survey: VOSviewer, a computer program for bibliometric mapping. Scientometrics 2010, 84, 523-538. [CrossRef] [PubMed]

38. Donohue, J.C. Understanding Scientific Literature: A Bibliographic Approach; The MIT Press: Cambridge, UK, 1973.

39. Valente, D.; Miglietta, P.P.; Porrini, D.; Pasimeni, M.R.; Zurlini, G.; Petrosillo, I. A first analysis on the need to integrate ecological aspects into financial insurance. Ecol. Model. 2019, 392, 117-127. [CrossRef]

40. Waltman, L.; Van Eck, N.J.; Noyons, E.C. A unified approach to mapping and clustering of bibliometric networks. J. Informetr. 2010, 4, 629-635. [CrossRef]

41. Waltman, L.; Van Eck, N.J. A smart local moving algorithm for large-scale modularity-based community detection. Eur. Phys. J. B 2013, 86, 1-14. [CrossRef]

42. Van Eck, N.J.; Waltman, L. How to normalize cooccurrence data? An analysis of some well-known similarity measures. J. Am. Soc. Inf. Sci. Technol. 2009, 60, 1635-1651. [CrossRef]

43. Sung, T.K. Industry 4.0: A Korea perspective. Technol. Forecast. Soc. Chang. 2018, 132, 40-45. [CrossRef] 
44. Kuo, C.C.; Shyu, J.Z.; Ding, K. Industrial revitalization via industry 4.0-A comparative policy analysis among China, Germany and the USA. Global Transit. 2019, 1, 3-14. [CrossRef]

45. Rojko, A. Industry 4.0 concept: Background and overview. Int. J. Interact. Mob. Technol. 2017, 11, 77-90. [CrossRef]

46. Manesh, M.F.; Pellegrini, M.M.; Marzi, G.; Dabic, M. Knowledge management in the fourth industrial revolution: Mapping the literature and scoping future avenues. IEEE Trans. Eng. Manag. 2020, 68, 289-300. [CrossRef]

47. Pichard, R.; Philippot, A.; Saddem, R.; Riera, B. Safety of manufacturing systems controllers by logical constraints with safety filter. IEEE Trans. Control Syst. Technol. 2018, 27, 1659-1667. [CrossRef]

48. Paez, A. Gray literature: An important resource in systematic reviews. J. Evid. Based Med. 2017, 10, 233-240. [CrossRef] [PubMed]

49. Agnusdei, G.P.; Elia, V.; Gnoni, M.G. A classification proposal of digital twin applications in the safety domain. Comput. Ind. Eng. 2021, 107137. [CrossRef]

50. Federmeccanica. Final Report INDUSTRY 4EU-Industry 4.0 for the Future of Manufacturing in Europe. Available online: http:/ / adapt.it/Industry4EU/INDUSTRY\%204EU_final_report.pdf (accessed on 24 February 2021).

51. Cimino, C.; Negri, E.; Fumagalli, L. Review of digital twin applications in manufacturing. Comput. Ind. 2019, 113, 103130. [CrossRef]

52. Oyekan, J.O.; Hutabarat, W.; Tiwari, A.; Grech, R.; Aung, M.H.; Mariani, M.P.; López-Dávalos, L.; Ricaud, T.; Singh, S.; Dupuis, C. The effectiveness of virtual environments in developing collaborative strategies between industrial robots and humans. Robot. Comput. Integr. Manuf. 2019, 55, 41-54. [CrossRef]

53. Nåfors, D.; Berglund, J.; Gong, L.; Johansson, B.; Sandberg, T.; Birberg, J. Application of a Hybrid Digital Twin Concept for Factory Layout Planning. Smart Sustain. Manuf. Syst. 2020, 4, 231-244. [CrossRef]

54. Brewer, T.; Knight, D.; Noiray, G.; Naik, H. Digital twin technology in the field reclaims offshore resources. In Proceedings of the Offshore Technology Conference, Houston, TX, USA, 6-9 May 2019.

55. Anderson, S.; Barvik, S.; Rabitoy, C. Innovative digital inspection methods. In Proceedings of the Offshore Technology Conference, Houston, TX, USA, 6-9 May 2019.

56. Boje, C.; Guerriero, A.; Kubicki, S.; Rezgui, Y. Towards a semantic Construction Digital Twin: Directions for future research. Autom. Constr. 2020, 114, 103179. [CrossRef]

57. Yuan, X.; Anumba, C.J. Cyber-Physical Systems for Temporary Structures Monitoring. In Cyber-Physical Systems in the Built Environment; Anumba, C.J., Roofigari-Esfahan, N., Eds.; Springer: Cham, Switzerland, 2020; pp. 107-138. [CrossRef]

58. Wanasinghe, T.R.; Wroblewski, L.; Petersen, B.; Gosine, R.G.; James, L.A.; De Silva, O.; Mann, G.K.I.; Warrian, P.J. Digital twin for the oil and gas industry: Overview, research trends, opportunities, and challenges. IEEE Access 2020, 8, 104175-104197. [CrossRef]

59. Malik, A.A.; Masood, T.; Bilberg, A. Virtual reality in manufacturing: Immersive and collaborative artificial-reality in design of human-robot workspace. Int. J. Comput. Integr. Manuf. 2020, 33, 22-37. [CrossRef]

60. Eckhart, M.; Ekelhart, A.; Weippl, E. Enhancing cyber situational awareness for cyber-physical systems through digital twins. In Proceedings of the 2019 24th IEEE International Conference on Emerging Technologies and Factory Automation (ETFA), Zaragoza, Spain, 10-13 September 2019; pp. 1222-1225.

61. Zohdi, T.I. A digital twin framework for machine learning optimization of aerial firefighting and pilot safety. Comput. Methods Appl. Mech. Eng. 2021, 373, 113446. [CrossRef]

62. Scheuermann, C.; Binderberger, T.; von Frankenberg, N.; Werner, A. Digital twin: A machine learning approach to predict individual stress levels in extreme environments. In Proceedings of the 2020 ACM International Joint Conference on Pervasive and Ubiquitous Computing and Proceedings of the 2020 ACM International Symposium on Wearable Computers, Cancùn, Mexico, 12-16 September 2020; pp. 657-664.

63. Dröder, K.; Bobka, P.; Germann, T.; Gabriel, F.; Dietrich, F. A machine learning-enhanced digital twin approach for human-robotcollaboration. Procedia CIRP 2018, 76, 187-192. [CrossRef]

64. Zandi, K.; Ransom, E.H.; Topac, T.; Chen, R.; Beniwal, S.; Blomfors, M.; Shu, J.; Chang, F.-K. A Framework for Digital Twin of Civil Infrastructure-Challenges \& Opportunities. Struct. Health Monit. 2019. [CrossRef]

65. Bottani, E.; Vignali, G.; Tancredi, G.P.C. A digital twin model of a pasteurization system for food beverages: Tools and architecture. In Proceedings of the 2020 IEEE International Conference on Engineering, Technology and Innovation (ICE/ITMC), Cardiff, UK, 15-17 June 2020; pp. 1-8.

66. Perez, G.C.; Korth, B. Digital Twin for Legal Requirements in Production and Logistics based on the Example of the Storage of Hazardous Substances. In Proceedings of the 2020 IEEE International Conference on Industrial Engineering and Engineering Management (IEEM), Singapore, 14-17 December 2020; pp. 1093-1097.

67. Li, W.; Rentemeister, M.; Badeda, J.; Jöst, D.; Schulte, D.; Sauer, D.U. Digital twin for battery systems: Cloud battery management system with online state-of-charge and state-of-health estimation. J. Energy Storage 2020, 30, 101557. [CrossRef] 